\title{
A dual-tracer method for differentiating transendothelial transport from paracellular leakage in vivo and in vitro
}

\section{Nino Muradashvili, Reeta Tyagi and David Lominadze*}

Department of Physiology and Biophysics, School of Medicine, University of Louisville, Louisville, KY, USA

\section{Edited by:}

James B. Hoying, Cardiovascular

Innovation Institute, USA

\section{Reviewed by:}

James B. Hoying, Cardiovascular Innovation Institute, USA

Thomas Paul Davis, University of Arizona College of Medicine, USA Richard Minshall, University of Illinois Hospital and Health Sciences System, USA

\section{*Correspondence:}

David Lominadze, Department of Physiology and Biophysics, School of Medicine, University of Louisville, Building A, Room 1115, 500 South Preston Street, Louisville, KY 40202, USA.

e-mail: david.lominadze@louisville.edu
Inflammation-induced impaired function of vascular endothelium may cause leakage of plasma proteins that can lead to edema. Proteins may leave the vascular lumen through two main paracellular and transcellular pathways. As the first involves endothelial cell (EC) junction proteins and the second caveolae formation, these two pathways are interconnected. Therefore, it is difficult to differentiate the prevailing role of one or the other pathway during pathology that causes inflammation. Here we present a newly developed dual-tracer probing method that allows differentiation of transcellular from paracellular transport during pathology. This fluorescence-based method can be used in vitro to test changes in EC layer permeability and in vivo in various animal vascular preparations. The method is based on comparison of low molecular weight molecule (LMWM) transport to that of high molecular weight molecule (HMWM) transport through the EC layer or the vascular wall during physiological and pathological conditions. Since the LMWM will leak through mainly the paracellular and HMWM will move through paracellular (when gaps between the ECs are wide enough) and transcellular pathways, the difference in transport rate (during normal conditions and pathology) of these molecules will indicate the prevailing transport pathway involved in overall protein crossing of vascular wall. Thus, the novel approach of assessing the transport kinetics of different size tracers in vivo by intravital microscopy can clarify questions related to identification of target pathways for drug delivery during various pathologies associated with elevated microvascular permeability.

Keywords: cerebrovascular leakage, intravital microscopy, fluorescent dyes

\section{INTRODUCTION}

Many inflammatory diseases such as hypertension (Johansson et al., 1978; Miller et al., 1986; Pedrinelli et al., 1999), diabetes (Bonnardel-Phu et al., 1999), and stroke (Hatashita and Hoff, 1990; Laursen et al., 1993; Wardlaw et al., 2003) are accompanied by impaired vascular wall integrity leading to enhanced microvascular leakage. Movement of plasma proteins to interstitium can be particularly detrimental as it is most likely a cause of edema. Proteins may cross endothelium through two main pathways: paracellular and transcellular. Paracellular transport occurs through gaps between endothelial cells (ECs) and involves alterations in tight, gap, and adherence junction proteins (Mehta and Malik, 2006). Transcellular transport occurs through the EC and involves formation of functional caveolae and their mobility (Stan et al., 1999; Stan, 2007). Since caveolae are attached to actin filaments through the protein filamin (Ushio-Fukai and Alexander, 2006) as are tight junction and adherence junction proteins (Mehta and Malik, 2006), and caveolae-mediated transcytosis and paracellular transport are interconnected (Bauer et al., 2005) the prevailing role of one or the other pathway in overall protein transvascular transport is difficult to define. Caveolin-1-null mice that lack caveolae in the endothelium showed increased permeability to albumin in venules and capillaries via the paracellular route (Razani et al., 2001; Miyawaki-Shimizu et al., 2006), suggesting a close crosstalk between transcellular and paracellular pathways in regulating tissue fluid balance.
Albumin, the most abundant plasma protein, constantly crosses the EC barrier in both directions (from the apical to the basal and from the basal to the apical side of cells) and acts as a chaperone for a number of hydrophobic molecules (Mehta and Malik, 2006). It is suggested that movement of albumin occurs through mainly transcellular transport (Mehta and Malik, 2006) since EC gaps are not readily opened to the extent to permit albumin leakage. During various inflammatory stimulations EC gaps open transiently leading to leakage of plasma components (including proteins, e.g., albumin) to the interstitium. However, formation of caveolae may be enhanced and lead to protein transport for a longer duration leading to edema. Thus there is a difference in action between these two transport pathways.

We developed a dual-tracer probing method to differentiate the relative involvement of transcellular and paracellular transport pathways in protein crossing the EC layer and vascular wall during pathology. This method is based on a comparison of leakage of a low molecular weight molecule (LMWM) and a high molecular weight molecule (HMWM; in our case albumin) through cultured mouse brain ECs (MBECs) and mouse pial venules during normal and pathological conditions. To test inflammation-induced possible changes in transcellular and paracellular transport, we used hyperfibrinogenemia (HFg) as the experimental pathology. HFg accompanies many inflammatory diseases such as hypertension (Letcher et al., 1981; Lominadze et al., 1998), diabetes (Lee et al., 2007), stroke (Eidelman and Hennekens, 2003; del Zoppo 
et al., 2009), and traumatic brain injury (Pahatouridis et al., 2010). We showed that enhanced blood content of fibrinogen (Fg) compromises EC layer integrity resulting in albumin leakage through cultured EC layer (Tyagi et al., 2008; Muradashvili et al., 2011) and mouse pial venules (Muradashvili et al., 2012). It was found that Fg causes enhanced movement of fluorescently labeled bovine serum albumin (BSA) through both transcellular and paracellular pathways (Tyagi et al., 2008; Muradashvili et al., 2011, 2012). However, the prevailing role of one or the other transport mechanism was not defined.

\section{METHODS}

\section{REAGENTS AND ANTIBODIES}

Human Fg (FIB-3, depleted of plasminogen, von-Willebrand factor, and fibronectin) was purchased from Enzyme Research Laboratories (South Bend, IN). Alexa Fluor 647-conjugated BSA (BSA647) was obtained from Invitrogen (Carlsbad, CA). Fluorescein isothiocyanate (FITC) and Lucifer Yellow were from Sigma Aldrich Chemicals Co. (St. Louis, MO).

\section{ANIMALS}

In accordance with National Institute of Health Guidelines for animal research, all animal procedures for these experiments were reviewed and approved by the Institutional Animal Care and Use Committee of the University of Louisville.

Male wild type (WT) C57BL/6J mice were from the Jackson Laboratory (Bar Harbor, ME). HFg transgenic mice on C57BL/6J background (strain name: C57BL/6Tg(Fga,Fgb,Fgg)1Unc/Mmnc; Stock Number 004104) were purchased from Mutant Mouse Regional Resource Center at the University of North Carolina at Chapel Hill (Chapel Hill, NC). For genotyping of HFg mice, DNA was extracted from the tail tip of mice and was amplified by polymerase chain reaction (PCR) using specific primer sequences according to the protocol provided by the Jackson Laboratory and described elsewhere (Gulledge et al., 2001). The primer sequences for HFg were forward 5'-GGC CGT CGA CAT TTA GGT GAC AC-3' and reverse 5'-AGT CAA TTT GGT CAC TAA CC GCC-3'. The primer sequences for WT were forward: 5'-GTG GGA CCA TCA TAA CAT CAC A-3'; reverse: 5'-CTC GCG GCA AGT CTT CAG AGT A-3'. Typical genotype results are presented on Figure 1. HFg mice have higher plasma levels of Fg than WT mice (Gulledge et al., 2001, 2003).

Twenty-week old mice (29-32 g) were anesthetized with sodium pentobarbital $(70 \mathrm{mg} / \mathrm{kg}$, IP). Supplemental anesthesia was given as required during the experiment. 2\% Xylocaine

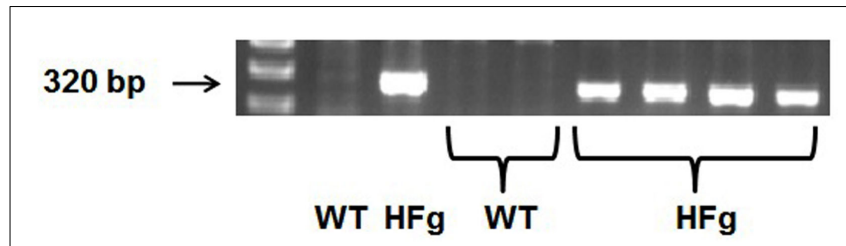

FIGURE 1 | Genotyping of hyperfibrinogenic (HFg) - fibrinogen transgene positive and wild type (WT) mice. Single PCR products suggest the homozygous mutation $(\mathrm{HFg})$, while its absence represents WT allele.
(AstraZeneca LP, Wilmington, DE) was used for local analgesia. The left carotid artery was cannulated with polyethylene tubing PE-10 for blood pressure monitoring and necessary infusions. The trachea was cannulated to maintain a patent airway. Body temperature of the mouse was kept at $37 \pm 1^{\circ} \mathrm{C}$ with a heating pad. Mean arterial blood pressure and heart rate were continuously monitored through a carotid artery cannula connected to a transducer and a blood pressure analyzer (CyQ 103/302, Cybersense, Lexington, KY). A tail cuff and a CODA monitor, a non-invasive blood pressure measurement system (Kent Scientific Apparatus, Torrington, CT), were used to monitor mean arterial blood pressure during infusion of dyes.

Brain pial microcirculation was prepared for observations according to the method described previously (Lominadze et al., 2006; Muradashvili et al., 2012).

\section{ENDOTHELIAL CELL CULTURE}

Mouse brain ECs were purchased from American Type Culture Collection (ATCC, Manassas, VA). The cells were cultured in complete Dulbecco's modified eagle's medium (DMEM), according to the manufacturer's (ATCC) recommendation, at $37^{\circ} \mathrm{C}$ with $5 \%$ $\mathrm{CO}_{2}$ /air in a humidified environment and were used at the 5 th or 6th passage for the experiments.

\section{DUAL-TRACER PROBING METHOD}

To determine changes in transcellular and paracellular transport mechanisms induced by enhanced blood content of Fg and to define if one of these pathways has a prevailing role during this pathology, we developed a dual-tracer probing method. In vitro, leakage of Lucifer yellow (as a LMWM) and Alexa Fluor 647conjugated BSA (BSA-647) through MBEC layer treated with $4 \mathrm{mg} / \mathrm{ml} \mathrm{Fg}$ or phosphate-buffered saline (PBS) was studied. In vivo, leakage of FITC (as a LMWM) was compared to that of BSA-647 in pial venules of normal WT and HFg mice.

\section{Microvascular leakage}

Mouse pial venular leakage was observed as described previously (Lominadze et al., 2006; Muradashvili et al., 2012). Following the surgical preparation and preceding each experiment, there was a 1-h equilibration period. Before each experiment, autofluorescence of the observed area was recorded over a standard range of camera gains. Mixture of $100 \mu \mathrm{l}$ of FITC $(300 \mu \mathrm{g} / \mathrm{ml})$ and $20 \mu \mathrm{l}$ of BSA-647 $(3.3 \mathrm{mg} / \mathrm{ml})$ in PBS (a total of $120 \mu \mathrm{l}$ solution) was infused through the carotid artery cannulation. The solution was infused with a syringe pump (Harvard Apparatus, Holliston, MA) at $30 \mu \mathrm{l} / \mathrm{min}$ speed and allowed to circulate for $10 \mathrm{~min}$ (Lominadze et al., 2006; Muradashvili et al., 2012). The pial circulation was surveyed to ensure that there was no spontaneous leakage of BSA-647 in the observed area that would indicate compromised vascular integrity. Venules were identified by observing the topology of the pial circulation and blood flow direction. Images of the selected third-order venular segments were recorded and used as baseline. After obtaining the baseline reading, images of the selected venular segments were recorded at 10, 20, 40,60, and $120 \mathrm{~min}$.

An epi-illumination system was used to observe intravascular and extravascular FITC and BSA-647. The area of interest was exposed to blue light $(488 \mathrm{~nm})$ and then red light $(647 \mathrm{~nm})$ for 10 $15 \mathrm{~s}$ with a power density of $3.5 \mu \mathrm{W} / \mathrm{cm}^{2}$. The microscope images 
were acquired by an electron-multiplying charge-coupled device camera (Quantem 512SC, Photometrics, Tucson, AZ) and image acquisition system (Slidebook 5.0, Intelligent Imaging Innovations, Inc., Philadelphia, PA). The camera output was standardized with a $50 \mathrm{ng} / \mathrm{ml}$ fluorescein diacetate standard (Estman Kodak, Rochester, NY) for each experiment. The lamp power and camera gain settings were held constant during experiments, and the camera response was verified to be linear over the range used for these acquisitions. The magnification of the system with Olympus $20 \times / 0.40$ (UPlanSApo) objective was determined with a stage micrometer.

Images of the pial venular circulation were analyzed by image analysis software (Image-Pro Plus 7.0, Media Cybernetics, Bethesda, MD). Example of the image analysis for detection of BSA-647 leakage to interstitium is presented on Figure 2. In each image, a Line Profile probe (LPP) of $50 \mu \mathrm{m}$ in length was positioned in the interstitium adjacent to a venular wall in parallel to the venule (Figure 2A) and then in the middle of the venule parallel to the blood stream (Figure 2B). Mean fluorescence intensities were measured for each dye (Figure 2). Leakage of FITC and BSA-647 to interstitium was assessed by changes in the ratio of fluorescence intensity of each dye in the interstitium to that inside the venule for the respective dye. The results were averaged for each experimental group and presented as percent of baseline. The diameter of each venule under observation was also measured.

\section{Leakage through EC layer}

Changes in transcellular and paracellular transport in cultured MBECs were studied using Transwell permeable supports (Corning Inc., Corning, NJ) as previously described (Tyagi et al., 2008; Patibandla et al., 2009). Briefly, the Transwell permeable supports
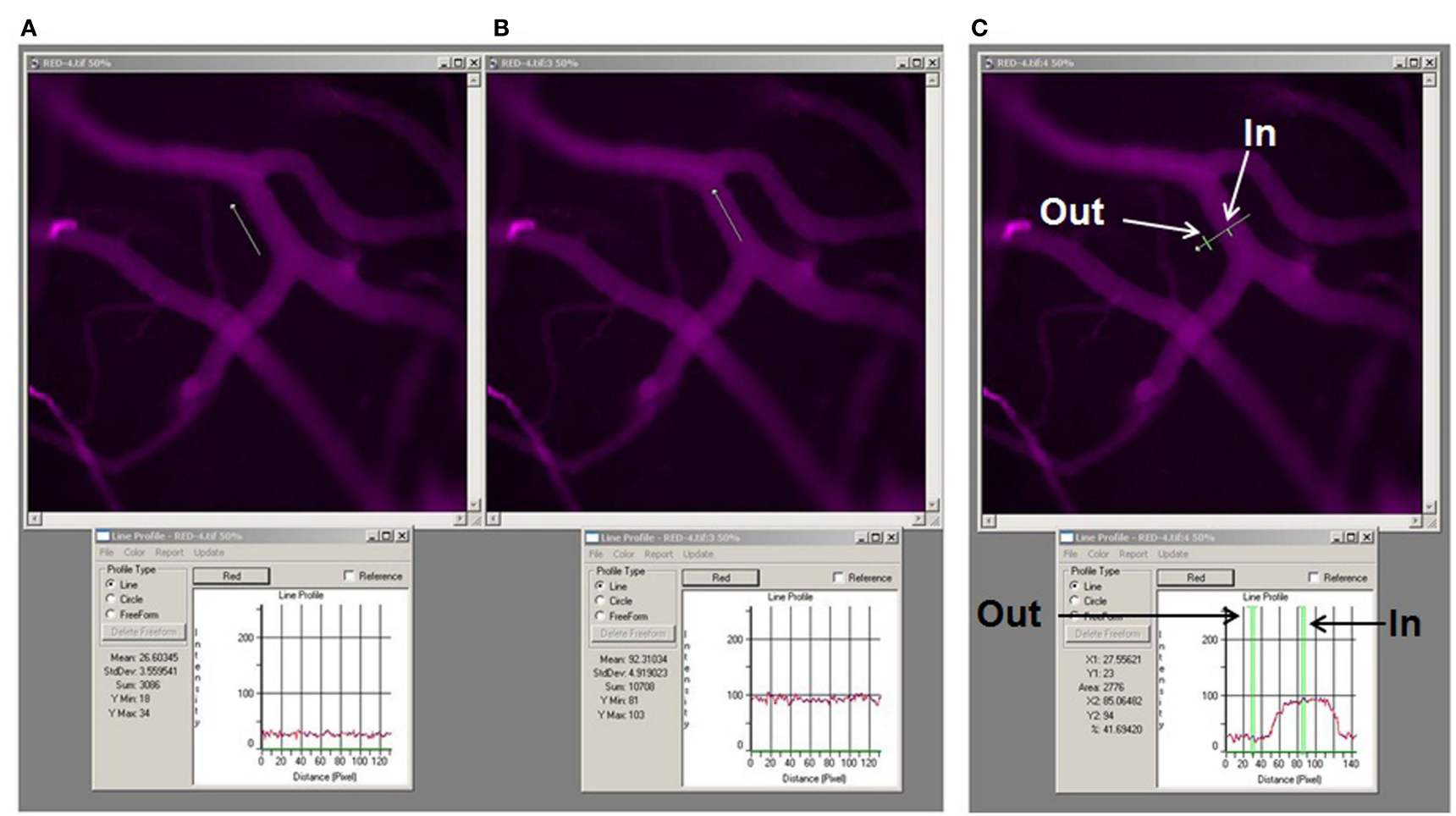

FIGURE 2 | Image analysis of microvascular leakage using Image-Pro Plus software. Examples of pial microvascular bed images (with circulating BSA-647) with a digital Line Profile probe (LPP) placed in the area of interest (upper row) and corresponding results of fluorescent light intensity readings shown in respective Line profile boxes (lower row). About thirty micrometer long LPP was first placed in interstitium adjacent to the venular segment (A) and then inside the venular segment (B). To perform quantitative analysis of fluorescence intensity along a LPP the following steps were followed:

$<$ Measure $>,<$ Line profile $>$ (this led to appearance of the Line profile box. The size and the place of the LPP on the image were adjusted manually), <Report $>$ in the Line profile box, then "statistics." For assessment of fluorescence intensity of BSA-647 < red > was chosen in the Line profile box, while <green $>$ was chosen for FITC intensity measurement. Values of the fluorescence intensities were given as "Mean" and "Standard deviation" in the Line profile box (see lower row). Fluorescence intensity profile along the LPP for each image is shown in the Line profile box below the respective image. Mean values averaged along the LPP are also shown in the Line profile box. Note that mean fluorescence intensity inside the venule is 92.3 fluorescence intensity units (FIU) and in the adjacent interstitium is 26.6 FIU. Thus ratio of fluorescence intensity in interstitium to that in the venule is 0.29 . This value was expressed as a percent of baseline values calculated for images obtained immediately after infusion of the dual-tracer probe. Example of the LPP placed across the venular segment and over the adjacent interstitium (upper image) with the fluorescence intensity profile along the LPP (below) is shown (C). Arrows indicate precise locations of where the fluorescence intensities were measured along the LPP. Note that fluorescence intensity inside the venule (In) is $85.1 \mathrm{FIU}$ and in interstitium (Out) is 23. Thus ratio of fluorescence intensity in interstitium to that in the venule in the marked places along the LPP is 0.27 . However, to obtain reliable data the LPP should be moved along the vessel and several measurements performed to calculate an average of these results. Since the same data, with better precision, can be obtained using the method described above $(\mathbf{A}, \mathbf{B})$, we placed the LPP across the vessel to define the vascular wall and the distance from the vessel where the LPP should have been placed (parallel to the vessel) in interstitium. 
with polycarbonate membranes (Nuclepore Track-Etch, $6.5 \mathrm{~mm}$ in diameter, $0.4 \mu \mathrm{m}$ pore size, and pore density of $10^{8} / \mathrm{cm}^{2}$ ) coated with fibronectin were seeded with MBECs and grown in DMEM until they formed a complete monolayer. Cell confluence and the presence of an intact monolayer on the membranes were confirmed in each series of experiments (Tyagi et al., 2008; Patibandla et al., 2009). To inhibit the effect of thrombin's activity, hirudin $(0.1 \mathrm{U} / \mathrm{ml})$ was added to each well in all experiments. The surface levels of solutions in the luminal $(200 \mu \mathrm{l})$ and abluminal $(600 \mu \mathrm{l})$ compartments of the Transwells were the same.

For the permeability assay, cells were washed with PBS and treated with $4 \mathrm{mg} / \mathrm{ml}$ of Fg or with medium alone in the presence of Lucifer yellow $(0.3 \mathrm{mg} / \mathrm{ml})$ and BSA-647 $(0.2 \mathrm{mg} / \mathrm{ml})$. After 10 , $20,40,60$, and $120 \mathrm{~min}$ media samples $(50 \mu \mathrm{l})$ were collected from lower chambers of the Transwell system and the same volume of the sample was added to the each appropriate upper well. Fluorescence intensity of each dye in samples were measured by a microplate reader (SpectraMax M2e, Molecular Devices Corporation, Sunnyvale, CA) with excitation at $488 \mathrm{~nm}$ and emission at $520 \mathrm{~nm}$ (cutoff $515 \mathrm{~nm}$ ) for Lucifer Yellow and with excitation at $650 \mathrm{~nm}$ and emission at $668 \mathrm{~nm}$ (cutoff $665 \mathrm{~nm}$ ) for BSA-647. Results are expressed as a ratio of fluorescence intensity of each dye in the bottom chamber (of each experimental group) to fluorescence intensity of the respective dye in the original sample (of the respective group) at the end of the experiment. Experiments were performed eight times for each treatment.

\section{DATA ANALYSIS}

All data are expressed as mean \pm SEM. The experimental groups were compared by one-way ANOVA with repeated measures. If ANOVA indicated a significant difference $(p<0.05)$, Tukey's multiple comparison test was used to compare group means. Differences were considered significant if $p<0.05$.

\section{RESULTS AND DISCUSSION}

Genotyping of experimental animals using appropriate primers and PCR positively identified HFg transgenic mice (Figure 1). Body weight of animals used in the study varied from 29 to $32 \mathrm{~g}$. Mean arterial blood pressure did not change in WT $(-1 \pm 0.5 \mathrm{mmHg})$ or in $\mathrm{HFg}(-3 \pm 0.5 \mathrm{mmHg})$ mice after FITC and BSA-647 infusion. During the observation period venular diameters $(38 \pm 6 \mu \mathrm{m})$ in WT animals changed insignificantly less $(+1 \pm 0.2 \mu \mathrm{m})$ than venular diameters $(40 \pm 5 \mu \mathrm{m})$ in HFg mice $(+2 \pm 0.6 \mu \mathrm{m})$.

We found that HFg caused greater leakage of plasma components through both transcellular and paracellular pathways (Figure 3). While the leakage of BSA-647 from pial venules was greater in HFg mice than that in WT mice starting from $20 \mathrm{~min}$ (Figure 3B), leakage of FITC was more in HFg mice than in WT mice only at 20 and $40 \mathrm{~min}$ (Figure 3A). Similarly, while at higher levels of Fg the leakage of BSA-647 through EC layer was greater starting from 20 min (Figure 3C), leakage of Lucifer Yellow through Fg-treated cells was more than that in control group only at 20 and $40 \mathrm{~min}$ (Figure 3D).

Stokes-Einstein radii of Lucifer Yellow $(\sim 0.49 \mathrm{~nm}$; Heyman and Burt, 2008) and FITC ( $\sim 0.45 \mathrm{~nm}$; Fu and Shen, 2003) are significantly less than that (3.5 nm) of BSA (Fu and Shen, 2003).
Therefore, in case of increased level of Fg that affects EC junctions and caveolae formation (Tyagi et al., 2008; Patibandla et al., 2009; Muradashvili et al., 2011, 2012), Lucifer Yellow (and FITC) may leak mainly through the cell junctions (Little et al., 1995), while BSA would leak through the cell junctions, when they are opened wide enough and traverse via the transcellular route, when caveolae-mediated transport is stimulated: more caveolae are formed and become functional (with enhanced mobility and ability of albumin endocytosis).

Thus, leakage of Lucifer Yellow through EC layer (in vitro) or leakage of FITC through pial venules (in vivo) induced by high level of Fg was greater than that in respective control groups starting from 20 min but was no longer different from the control groups at 60 and $120 \mathrm{~min}$ (Figure 3). This data may indicate that after $40 \mathrm{~min}$ Fg no longer had an effect on EC gap formation. However, leakage of BSA-647 in vitro and in vivo induced by high level of Fg was greater than that in respective control groups from $40 \mathrm{~min}$ and continued to rise with time (Figure 3 ). These results suggest that Fg affects junction proteins (JPs) and leads to a transient opening of gaps between cells enhancing the leakage of LMWMs (Lucifer Yellow or FITC). This notion is supported by our data showing that Fg can cause translocation of JPs (Patibandla et al., 2009). As the effect of Fg on JPs subsides, the difference in Lucifer Yellow or FITC leakage between the HFg and the control groups vanish. However, high level Fg-induced leakage of HMWM (BSA) increases even after the paracellular pathway is no longer stimulated by Fg (Figures 3A,C). Thus BSA may move through MBEC layer and through pial venular wall first through both transport pathways and later (after relative closure of the junctional gaps) by mostly transcytosis.

The complicated nature of microvascular permeability was defined long ago using intravital microscopy and light absorbing dyes (Landis, 1927). Nakamura and Wayland (1975) tested leakage of fluorescently tagged BSA and various molecular weight dextrans. The leakage of these tracers was tested one at a time (Nakamura and Wayland, 1975). Even earlier, Witte (1965) used fluorescent tracers in qualitative studies on extravascular circulation in both normal and pathological conditions in mammals. Since then there were numerous reports related to microvascular or EC layer permeability using fluorescent dyes. However, none of them compared leakage kinetics of two different size tracers occurring at relatively the same time course in normal and pathological conditions.

Use of fluorescent and radioactive tracers to better define mechanisms of endothelial or vascular permeability continued. Vogel et al. (2001) define their method as a "single-sample" technique of Kern et al. (1983). Later John et al. (2003) presented quantitative analysis of albumin uptake and transport in ECs in vitro using ${ }^{125} \mathrm{I}$-albumin. Its leakage through the EC layer was compared to that of unlabeled albumin. The authors showed that transcellular uptake and transport of ${ }^{125} \mathrm{I}$-albumin can be blocked by excess of native albumin, and that any remaining leakage in these Transwell assays was via gaps in the monolayer. The results also indicated that albumin internalized and transported via caveolae can be distinguished in overall transendothelial albumin transport through the EC barrier in vitro. This method, which defines internalization of albumin in caveolae, was also used to demonstrate 

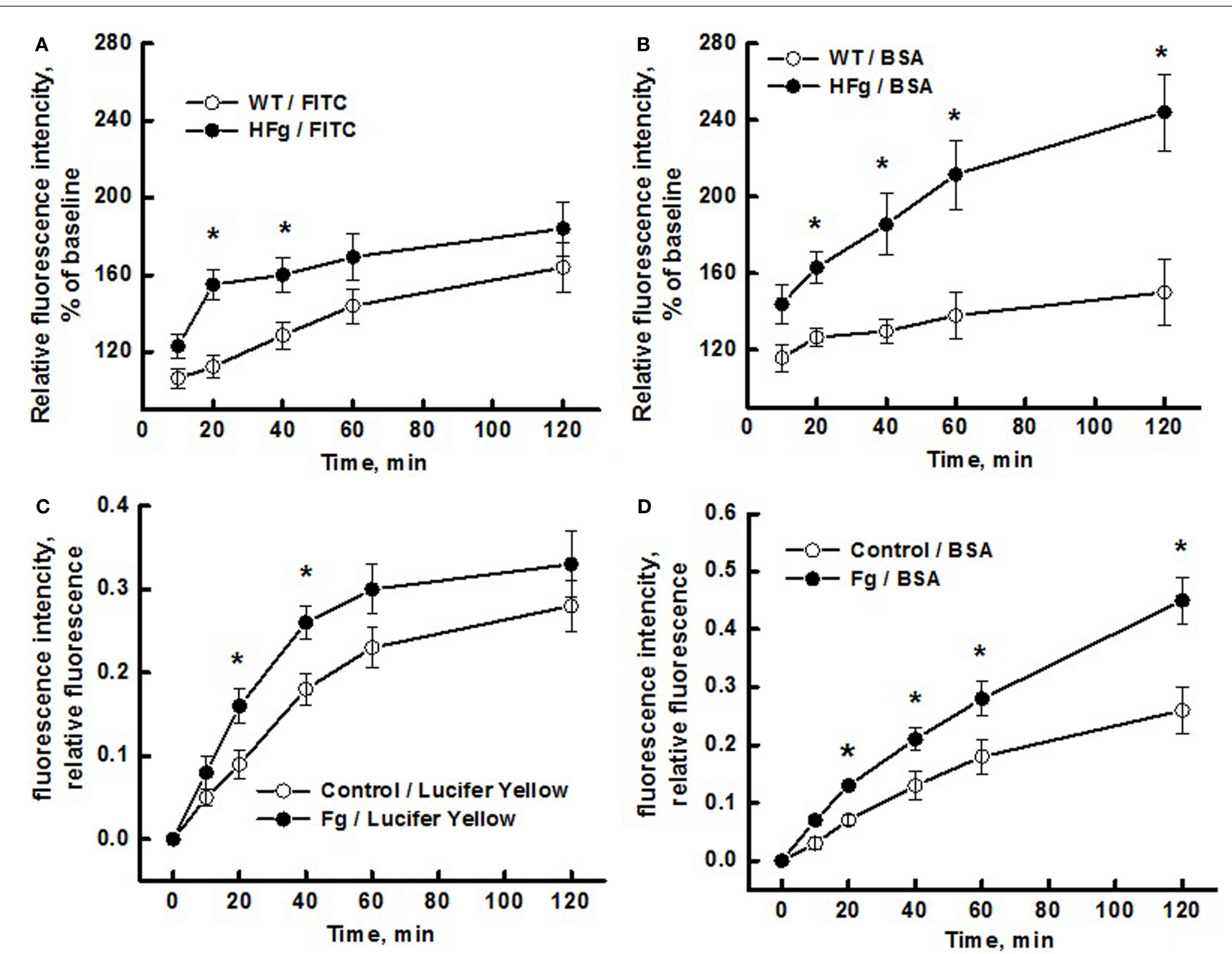

FIGURE 3 | Differentiation of transcellular from paracellular transport through microvascular wall and endothelial cell (EC) layer using a dual-tracer probing method. Leakage of fluorescein isothiocyanate (FITC; upper left panel) or Lucifer Yellow (bottom left panel) and Alexa Fluor 647-conjugated bovine serum albumin BSA (BSA-647; right column) was studied in pial venules of wild type (WT) and hyperfibrinogenic (HFg) mice $(\mathbf{A}, \mathbf{B})$, and in mouse brain ECs (MBECs) treated with medium alone (control) or with $4 \mathrm{mg} / \mathrm{ml}$ of $\mathrm{Fg}$ in medium (Fg) (C,D). Leakage of FITC was greater in HFg mice at 20 and 40 min after infusion of the dye but at 60 and 120 min the difference was no longer observed (A). However, leakage of BSA-647 was more in HFg mice after 20 min of dye infusion (B). These results indicate that inflammatory changes caused by HFg mediate a

that by interacting with the actin crosslinking protein filamin A, caveoalin-1 phosphorylation plays a critical role in the mechanism of caveolae-mediated transcytosis and thereby stimulates transcellular permeability (Sverdlov et al., 2009).

Kovar et al. (1997) compared low and high molecular weight tracers to investigate perfusion rate in rodent tumors. Use of two tracers, sodium fluorescein and Texas red-dextran $(70 \mathrm{kD})$, has been reported by Russ et al. (2001). The first tracer was used to indicate vessel leak and the second to indicate vessel filling. Again, this study did not differentiate transcellular and paracellular transport. Hu et al. (2008) demonstrated a novel transient opening of the EC junction gaps after infusion of the dye causing the leakage of FITC. However, when the gaps are no longer opened more in HFg mice than in WT mice, enhanced caveolae formation and their function still maintains greater leakage of BSA via transcellular transport. Similarly, the leakage of Lucifer Yellow was greater through MBECs treated with $4 \mathrm{mg} / \mathrm{ml}$ of $\mathrm{Fg}$ at 20 and $40 \mathrm{~min}$ after addition of the dye but at 60 and $120 \mathrm{~min}$ the difference was no longer observed (C). However, leakage of BSA-647 was more through the MBECs treated with Fg after 20 min of addition of dyes (D). These results confirm the data obtained for mouse pial venules, indicating that HFg affects mainly the transcellular transport through formation of functional caveolae. ${ }^{*} p<0.05-$ versus WT or control. $n=6$ for animals and $n=8$ MBECs. role of caveolae-mediated albumin transport in microvascular inflammatory hyperpermeability. They showed that intercellular adhesion molecule-1 activation-dependent caveolin-1 phosphorylation stimulated transcytosis of albumin in the pulmonary vasculature and that this increase in inflammatory transcellular albumin hyperpermeability $\left({ }^{125} \mathrm{I}\right.$-albumin permeability surface area product) as well as the increase in capillary filtration coefficient (fluid permeability) was abolished in caveolin-1 knockout mouse lungs. Leakage of ${ }^{125} \mathrm{I}$-albumin through ECs was compared to that of ${ }^{3} \mathrm{H}$-mannitol, a low-molecular-weight (182-Da) tracer that traverses the endothelium via the paracellular pathway. However, 
authors did not record time-dependent changes in leakage of these tracers. Therefore, the method did not show if albumin leaked more via the paracellular or transcellular pathway. In addition, this was not the aim of the study.

A two-tracer isotope method using albumin labeled with ${ }^{131} \mathrm{I}$ and ${ }^{125} \mathrm{I}$ was used previously to define accumulation of albumin in vascular and extravascular space of various tissue (Tucker et al., 1992). Although it has been emphasized that the advantages of the two-tracer isotope methods to investigate transvascular macromolecule transport are becoming more widely recognized (Nagy et al., 2008), their use with transgenic mouse models has been limited. Lately this method has been used with better success to define the effects of atrial natriuretic peptide in microvascular permeability (Curry et al., 2010). However, as the two-tracer isotope method uses the same molecule with two different tracers, the method may not differentiate between the involvement of transcellular or paracellular transport pathways in total microvascular permeability. In another study, alterations in blood brain barrier permeability were studied using Evans blue and ${ }^{125}$ I-taged albu$\min (\mathrm{Nag}, 1991)$. However, the probes were infused at separate times and no time-dependent observation of the vascular leakage was performed (Nag, 1991).

Our data indicate that using the newly developed dual-tracer probing method allows differentiation of the relative involvement of transcellular and paracellular transport pathways in inflammation-induced vascular and EC layer permeability. Since the method is based on comparison of leakage of LMWM and HMWM during pathology, we conclude that it can be used during various pathologies to differentiate the role of transcellular versus paracellular transport in overall vascular or EC layer permeability. In addition, by assessing the rate (kinetics) of leakage of small and larger molecules the method may also allow the assessment of the difference in response time between paracellular and transcellular protein transport.

\section{LIMITATIONS OF THE METHOD}

It has been shown that the addition of fluorescent dyes can alter the physicochemical characteristics of water-soluble macromolecules (Bingaman et al., 2003). It was found that the greatest changes were observed for BSA when it was conjugated with FITC (Bingaman et al., 2003). Therefore, in our study we used BSA that was conjugated with Alexa-647. However, properties of BSA still may have been different from that of unconjugated BSA. This may have less significance as we compared leakage of the dye alone or dyeconjugated BSA in the same type of vessels (venules) between the animals (or ECs).

\section{REFERENCES}

Bauer, P. M., Yu, J., Chen, Y., Hickey, R., Bernatchez, P. N., LooftWilson, R., Huang, Y., Giordano, F., Stan, R. V., and Sessa, W. C. (2005). Endothelial-specific expression of caveolin-1 impairs microvascular permeability and angiogenesis. Proc. Natl. Acad. Sci. U.S.A. 102, 204-209.

Bingaman, S., Huxley, V. H., and Rumbaut, R. E. (2003). Fluorescent dyes modify properties of proteins used

Since we measured only the relative fluorescence intensity (in the interstitial space adjacent to a pial venule over the fluorescence intensity inside the vessel) and did not evaluate hydrostatic pressure in the venule, we could not asses the venular permeability to LMWM (FITC) as required by Starling's concept. We made an assumption that leakage of LMWM (FITC) through the vascular wall occurs via the paracellular pathway and any changes in this process may occur due to pathology (HFg in our case) causing alterations in this pathway. Presented data indicate an accumulation of BSA-647 in interstitium, which can be considered an adequate measure for venular permeability to proteins. In addition, we did not find a difference in vascular diameters and MABPs in response to dual-tracer probe infusion in both groups of mice.

Thus, the precision of the presented approach is based on the ability to make a pairwise comparison of simultaneously assessed leakage kinetics of small and large molecules during normal and pathological conditions. Therefore, this method does not provide quantitative assessment for one or the other transport pathway in overall protein leakage. It defines if one or the other pathway prevails in total protein leakage.

There are several methods for quantitative analysis of endothelial permeability, which are discussed by Mehta and Malik (2006). It seems that the most adequate technique for quantitative assessment of microvascular permeability can be the method that uses an isolated vessel (He et al., 2006). This method is based on the modified Landis technique (Curry et al., 1976). Quantitative assessment of EC layer permeability can be best performed with the methods discussed above and presented elsewhere (John et al., 2003; Hu et al., 2008).

In addition, due to competition with endogenous albumin the sensitivity of fluorescently labeled BSA (infused in small quantities into the circulation) in detecting transcytosis is limited. Possible use of dextrans (instead of albumin) may exclude receptor-mediated specificity typically involved in caveolae-mediated albumin transcytosis (Tiruppathi et al., 1997).

Since the Stokes-Einstein radius of Lucifer Yellow is slightly greater than that of FITC, we used the Lucifer Yellow as a LMWM in vitro. In preliminary experiments, we found that $100 \mu \mathrm{l}$ of Lucifer Yellow $(3 \mathrm{mg} / \mathrm{ml})$ did not produce detectable fluorescent light in vivo.

\section{ACKNOWLEDGMENTS}

Supported in part by the NIH grant HL-80394 (to David Lominadze).

low molecular weight hydrophilic solutes measured in single perfused capillaries of the frog mesentery. J. Physiol. (Lond.) 261, 319-336.

Curry, F.-R. E., Rygh, C. B., Karlsen, T., Wiig, H., Adamson, R. H., Clark, J. F., Lin, Y.-C., Gassner, B., Thorsen, F., Moen, I., Tenstad, O., Kuhn, M., and Reed, R. K. (2010). Atrial natriuretic peptide modulation of albumin clearance and contrast agent permeability in mouse skeletal muscle and skin: role in regulation of plasma volume. J. Physiol. (Lond.) 588, 325-339.

del Zoppo, G. J., Levy, D. E., Wasiewski, W. W., Pancioli, A. M., Demchuk, A. M., Trammel, J., Demaerschalk, B. M., Kaste, M., Albers, G. W., and Ringelstein, E. B. (2009). Hyperfibrinogenemia and functional outcome from acute ischemic stroke. Stroke 40, 1687-1691.

Curry, F. E., Michel, C. C., and Mason, J. C. (1976). Osmotic reflextion coefficients of capillary walls to
Eidelman, R. S., and Hennekens, C. H. (2003). Fibrinogen: a predictor of 
stroke and marker of atherosclerosis. Eur. Heart J. 24, 499-500.

Fu, B. M., and Shen, S. (2003). Structural mechanisms of acute VEGF effect on microvessel permeability. Am. J. Physiol. Heart Circ. Physiol. 284, H2124-H2135.

Gulledge, A., Rezaee, F., Verheijen, J., and Lord, S. (2001). A novel transgenic mouse model of hyperfibrinogenemia. Thromb. Haemost. 86, 511-516.

Gulledge, A. A., McShea, C., Schwartz, T., Koch, G., and Lord, S. T. (2003). Effects of hyperfibrinogenemia on vasculature of C57BL/6 mice with and without atherogenic diet. Arterioscler. Thromb. Vasc. Biol. 23, 130-135.

Hatashita, S., and Hoff, J. (1990). Brain edema and cerebrovascular permeability during cerebral ischemia in rats. Stroke 21, 582-588.

He, P., Zhang, H., Zhu, L., Jiang, Y., and Zhou, X. (2006). Leukocyte-platelet aggregate adhesion and vascular permeability in intact microvessels: role of activated endothelial cells. Am. J. Physiol. Heart Circ. Physiol. 291, H591-H599.

Heyman, N. S., and Burt, J. M. (2008). Hindered diffusion through an aqueous pore describes invariant dye selectivity of $\mathrm{Cx} 43$ junctions. Biophys. J. 94, 840-854.

Hu, G., Vogel, S. M., Schwartz, D. E., Malik, A. B., and Minshall, R. D. (2008). Intercellular adhesion molecule-1-dependent neutrophil adhesion to endothelial cells induces caveolae-mediated pulmonary vascular hyperpermeability. Circ. Res. 102, e120-e131.

Johansson, B. B., Linder, L.-E., and Persson, L. I. (1978). Hypertensioninduced protein leakage in the brain in ethanol-intoxicated conscious and anesthetized rats. Acta Neurol. Scand. 58, 333-339.

John, T. A., Vogel, S. M., Tiruppathi, C., Malik, A. B., and Minshall, R. D. (2003). Quantitative analysis of albumin uptake and transport in the rat microvessel endothelial monolayer. Am. J. Physiol. Lung Cell. Mol. Physiol. 284, L187-L196.

Kern, D. F., Levitt, D., and Wangensteen, D. (1983). Endothelial albumin permeability measured with a new technique in perfused rabbit lung. $A m$. J. Physiol. Heart Circ. Physiol. 245, H229-H236.

Kovar, D. A., Lewis, M. Z., River, J. N., Lipton, M. J., and Karczmar, G. S. (1997) In vivo imaging of extraction fraction of low molecular weight MR contrast agents and perfusion rate in rodent tumors. Magn. Reson. Med. $38,259-268$.
Landis, E. (1927). Microinjection studies of capillary permeability. II. Relationship between capillary pressure and the rate at which fluid passes through the wall of single capillaries. Am. J. Physiol. 82, 217-238.

Laursen, H., Hansen, A. J., and Sheardown, M. (1993). Cerebrovascular permeability and brain edema after cortical photochemical infarcts in the rat. Acta Neuropathol. 86, 378-385.

Lee, A. J., Lowe, G. D. O., Woodward, M., and Tunstall-Pedoe, $\mathrm{H}$. (2007). Fibrinogen in relation to personal history of prevalent hypertension, diabetes, stroke, intermittent claudication, coronary heart disease, and family history: the Scottish Heart Health Study. Br. Heart J. 69, 338-342.

Letcher, R. L., Chien, S., Pickering, T. G., Sealey, J. E., and Laragh, J. H. (1981). Direct relationship between blood pressure and blood viscosity in normal and hypertensive subjects. Role of fibrinogen and concentration. Am. J. Med. 70, 1195-1202.

Little, T. L., Xia, J., and Duling, B. R. (1995). Dye tracers define differential endothelial and smooth muscle coupling patterns within the arteriolar wall. Circ. Res. 76, 498-504.

Lominadze, D., Joshua, I. G., and Schuschke, D. A. (1998). Increased erythrocyte aggregation in spontaneously hypertensive rats. Am. J. Hypertens 11, 784-789.

Lominadze, D., Roberts, A. M., Tyagi, N., and Tyagi, S. C. (2006). Homocysteine causes cerebrovascular leakage in mice. Am. J. Physiol. Heart Circ. Physiol. 290, H1206-H1213.

Mehta, D., and Malik, A. B. (2006). Signaling mechanisms regulating endothelial permeability. Physiol. Rev. 86, 279-367.

Miller, F. N., Joshua, I. G., Fleming, J. T., and Parekh, N. (1986). Histamineinduced protein leakage in hypertensive rats: inhibition by verapamil. Am. J. Physiol. Heart Circ. Physiol. 250, H284-H290.

Miyawaki-Shimizu, K., Predescu, D., Shimizu, J., Broman, M., Predescu, S., and Malik, A. B. (2006). siRNAinduced caveolin-1 knockdown in mice increases lung vascular permeability via the junctional pathway. Am. J. Physiol. Lung Cell. Mol. Physiol. 290, L405-L413.

Muradashvili, N., Qipshidze, N., Munjal, C., Givvimani, S., Benton, R. L., Roberts, A. M., Tyagi, S. C., and Lominadze, D. (2012). Fibrinogeninduced increased pial venular permeability in mice. J. Cereb. Blood Flow Metab. 32, 150-163.
Muradashvili, N., Tyagi, N., Tyagi, R., Munjal, C., and Lominadze, D. (2011). Fibrinogen alters mouse brain endothelial cell layer integrity affecting vascular endothelial cadherin. Biochem. Biophys. Res. Commun. 413, 509-514.

Nag, S. (1991). Protective effect of flunarizine on blood-brain barrier permeability alterations in acutely hypertensive rats. Stroke 22, 1265-1269.

Nagy, J., Benjamin, L., Zeng, H., Dvorak, A., and Dvorak, H. (2008). Vascular permeability, vascular hyperpermeability and angiogenesis. Angiogenesis 11, 109-119.

Nakamura, Y., and Wayland, H. (1975). Macromolecular transport in the cat mesentery. Microvasc. Res. 9, 1-21.

Pahatouridis, D., Alexiou, G., Zigouris, A., Mihos, E., Drosos, D., and Voulgaris, S. (2010). Coagulopathy in moderate head injury. The role of early administration of low molecular weight heparin. Brain Inj. 24, 1189-1192.

Patibandla, P. K., Tyagi, N., Dean, W. L., Tyagi, S. C., Roberts, A. M., and Lominadze, D. (2009). Fibrinogen induces alterations of endothelial cell tight junction proteins. J. Cell. Physiol. 221, 195-203.

Pedrinelli, R., Penno, G., Dell'Omo, G., Bandinelli, S., Giorgi, D., Di Bello, V., Navalesi, R., and Mariani, M. (1999). Microalbuminuria and transcapillary albumin leakage in essential hypertension. Hypertension 34, 491-495.

Razani, B., Engelman, J. A., Wang, X. B., Schubert, W., Zhang, X. L., Marks, C. B., Macaluso, F., Russell, R. G., Li, M., Pestell, R. G., Di Vizio, D., Hou, H., Kneitz, B., Lagaud, G., Christ, G. J., Edelmann, W., and Lisanti, M. P. (2001). Caveolin-1 null mice are viable but show evidence of hyperproliferative and vascular abnormalities. J. Biol. Chem. 276, 38121-38138.

Russ, P. K., Gaylord, G. M., and Haselton, F. R. (2001). Retinal vascular permeability determined by dual-tracer fluorescence angiography. Ann. Biomed. Eng. 29, 638-647.

Stan, R. V. (2007). Endothelial stomatal and fenestral diaphragms in normal vessels and angiogenesis. J. Cell. Mol. Med. 11, 621-643.

Stan, R.-V., Marion, K., and Palade, G. E. (1999). PV-1 is a component of the fenestral and stomatal diaphragms in fenestrated endothelia. Proc. Natl. Acad. Sci. U.S.A. 96, 13203-13207.

Sverdlov, M., Shinin, V., Place, A. T., Castellon, M., and Minshall, R. D. (2009). Filamin A regulates caveolae internalization and trafficking in endothelial cells. Mol. Biol. Cell 20, 4531-4540.

Tiruppathi, C., Song, W., Bergenfeldt, M., Sass, P., and Malik, A. B. (1997). Gp60 Activation mediates albumin transcytosis in endothelial cells by tyrosine kinase-dependent pathway. J. Biol. Chem. 272, 25968-25975.

Tucker, V., Simanonok, K., and Renkin, E. (1992). Tissue-specific effects of physiological ANP infusion on blood-tissue albumin transport. Am J. Physiol. 263, R945-R953.

Tyagi, N., Roberts, A. M., Dean, W. L., Tyagi, S. C., and Lominadze, D. (2008). Fibrinogen induces endothelial cell permeability. Mol. Cell. Biochem. 307, 13-22.

Ushio-Fukai, M., and Alexander, R. W. (2006). Caveolin-dependent angiotensin II type 1 receptor signaling in vascular smooth muscle. Hypertension 48, 797-803.

Vogel, S. M., Minshall, R. D., Pilipovic, M., Tiruppathi, C., and Malik, A. B. (2001). Albumin uptake and transcytosis in endothelial cells in vivo induced by albumin-binding protein. Am. J. Physiol. Lung Cell. Mol. Physiol. 281, L1512-L1522.

Wardlaw, J. M., Sandercock, P. A. G., Dennis, M. S., and Starr, J. (2003). Is breakdown of the blood-brain barrier responsible for lacunar stroke, leukoaraiosis, and dementia? Stroke $34,806-812$.

Witte, S. (1965). Investigations of transvascular plasma passage with fluorescent microscopic technique. Bibl. Anat. 7, 218-222.

Conflict of Interest Statement: The authors declare that the research was conducted in the absence of any commercial or financial relationships that could be construed as a potential conflict of interest.

Received: 03 April 2012; accepted: 08 May 2012; published online: 31 May 2012.

Citation: Muradashvili N, Tyagi $R$ and Lominadze D (2012) A dual-tracer method for differentiating transendothelial transport from paracellular leakage in vivo and in vitro. Front. Physio. 3:166. doi: 10.3389/fphys.2012.00166

This article was submitted to Frontiers in Vascular Physiology, a specialty of Frontiers in Physiology.

Copyright (๑) 2012 Muradashvili, Tyagi and Lominadze. This is an open-access article distributed under the terms of the Creative Commons Attribution Non Commercial License, which permits noncommercial use, distribution, and reproduction in other forums, provided the original authors and source are credited. 